\title{
War and the Practice of Psychotherapy: The UK Experience 1939-1960
}

\author{
EDGAR JONES*
}

During the Second World War, it is argued, "the neuroses of battle" not only deepened an understanding of "psychopathological mechanisms", ${ }^{1}$ but also created opportunities for the practice of psychotherapy, while its perceived efficacy led to a broader acceptance within medicine and society once peace had returned. ${ }^{2}$ This recognition is contrasted with the aftermath of the First World War when a network of outpatient clinics, set up by the Ministry of Pensions to treat veterans with shell shock, were closed within a few years in response to financial pressures and doubts about their therapeutic value. In the private sector, psychoanalysis under the leadership of Ernest Jones remained an idiosyncratic activity confined largely to the affluent middle classes of London. ${ }^{3}$ According to Gregorio Kohon, "it was strongly opposed by the general public, the Church, the medical and psychiatric establishment, and the press". ${ }^{4}$ The Medico-Psychological Clinic of London, originally set up in 1913, offered psychotherapy on three afternoons a week in premises at 30 Brunswick Square under the direction of Dr James Glover. However, it closed in 1923 after Glover and his brother Edward had both become psychoanalysts. ${ }^{5}$ As the First World War drew to a close, Maurice Craig helped to persuade Sir Ernest Cassel to fund a hospital for 'Functional and Nervous Disorders' at Penshurst, Kent, to treat neuroses in the civilian population. ${ }^{6}$ Although moved to permanent premises near Richmond, it remained smallscale and at the time no attempt was made to establish a network of similar institutions throughout the UK. The Tavistock Clinic, opened in Bloomsbury in 1920, struggled to secure funding throughout the interwar period and its efforts to win official recognition from the University of London were consistently rebutted. ${ }^{7}$ Thus, despite the epidemic of shell shock and other so-called war neuroses, psychotherapy remained a marginal activity during the 1920 s and 1930s.

\footnotetext{
* Edgar Jones, PhD, Institute of Psychiatry \& Guy's King's and St Thomas' School of Medicine,

Department of Psychological Medicine, 103 Denmark Hill, London SE5 8AZ.

The author wishes to thank Dr Patrick de Maré, Dr Derry Macdiarmid, Dr Malcom Pines, Dr Bernie Rosen and Christine Thomas for their help in the research of this paper. The comments of the editors, Dr Michael Neve and Dr Harry Oosterhuis, were also much appreciated.

${ }^{1} \mathrm{~J}$ R Rees, The shaping of psychiatry by war, New York, W W Norton, 1945, p. 116.

${ }^{2}$ Eric Rayner, The independent mind in British psychoanalysis, London, Free Association Books, 1990, p. 268.
}

\footnotetext{
${ }^{3}$ Ben Shephard, A war of nerves, soldiers and psychiatrists 1914-1994, London, Jonathan Cape, 2000, p. 164.

${ }^{4}$ Gregorio Kohon, 'Notes on the history of the psychoanalytic movement in Great Britain', in $\mathrm{G}$ Kohon (ed.), The British school of psychoanalysis: the independent tradition, London, Free Association Books, 1986, pp. 24-50, on p. 28.

${ }^{5} \mathrm{~L}$ S Hearnshaw, A short history of British psychology, 1840-1940, London, Methuen, 1964. p. 165.

${ }^{6}$ H C Cameron, 'Sir Maurice Craig', Guy's Hospital Reports, 1935, 85: 251-7, p. 254.

${ }^{7} \mathrm{H}$ V Dicks, Fifty years of the Tavistock Clinic, London, Routledge \& Kegan Paul, 1970, pp. 61-3, 101 .
} 
During the Second World War, or so the argument goes, the need to return every psychiatric battle casualty to active duty, or at the very least to productive employment in civilian life, created important opportunities for therapists. ${ }^{8}$ Both psychiatrists and psychologists were recruited into the Royal Army Medical Corps (RAMC) where they experimented with novel treatments, ${ }^{9}$ drawing on ideas from psychoanalysis and social psychology. The work of Wilfrid Bion, John Rickman and Michael Foulkes at Northfield and Maxwell Jones at Mill Hill is said to have transformed the role of groups, while occupational, art and individual therapies advanced in psychiatric hospitals run by or for the military. ${ }^{10}$ Having proved their worth in wartime, these clinical services were adopted within the National Health Service and in the private sector. ${ }^{11}$ The war, it is suggested, had served as a significant catalyst for change and innovation.

By way of re-interpretation, it is proposed here that wartime psychotherapy was not as efficacious as claimed. Servicemen were not by and large returned to active duty, and many were downgraded or discharged after treatment. Published accounts may have been biased by questions of morale to exaggerate clinical effectiveness. Hence, when these techniques were introduced in the post-war health service they were accompanied by expectations raised beyond what might be reasonably achieved. This occurred at a time when attitudes towards the nature of mental illness and role of psychotherapy, at least within psychiatry and psychology, were in a state of flux. In an economy characterized by rationing, finite resources placed severe constraints on what could be provided in the public sector and these inflated results plausibly did no service to the long-term development of psychodynamic treatments.

\section{Definitions}

No satisfactory definition of psychotherapy exists, largely because of its broad clinical application and dissension within training organizations as to its theoretical basis. However, David Malan summarized the basic principles of dynamic psychotherapy as a relationship between patient and therapist designed to enable the former "to understand his true feelings and to bring them to the surface and experience them". ${ }^{12}$ As a treatment directed towards psychological self-awareness, it embraced both short focused interventions and long-term, five times a week therapies, together with individual or group approaches. Although psychoanalysis was the dominant model during the Second World War, it was characterized by theoretical disagreement and fissure. ${ }^{13}$ Furthermore, most doctors who practised

\footnotetext{
${ }^{8}$ Joanna Bourke, 'Psychology at war', in G C Bunn, A D Lovie and G D Richards (eds), Psychology in Britain: historical essays and personal reflections, Leicester, BPS Books, 2001, pp. 133-49, on pp. 134, 138.

${ }^{9} \mathrm{R} \mathrm{H}$ Ahrenfeldt, Psychiatry in the British army in the Second World War, London, Routledge \& Kegan Paul, 1958, pp. 147-62.

${ }^{10} \mathrm{R}$ H Ahrenfeldt, 'The army psychiatric service', in Arthur Salusbury MacNalty and W Franklin Mellor (eds), Medical services in war: the principal medical lessons of the Second World
}

War, London, HMSO, 1968, pp. 175-216, on pp. 200-3.

${ }^{11}$ Malcolm Pines, 'The development of the psychodynamic movement', in German Berrios and Hugh Freeman (eds), 150 years of British psychiatry 1841-1991, London, Gaskell, 1991, pp. 206-31, p. 229.

${ }^{12}$ David H Malan, Individual psychotherapy and the science of psychodynamics, London, Butterworth, 1979, p. 74.

${ }^{13}$ Pearl King and Ricardo Steiner (eds), The Freud-Klein controversies 1941-1945, London, Tavistock/Routledge, 1991. 
psychotherapy in a military setting were not psychoanalysts but psychiatric specialists with an interest in unconscious processes. It would be wrong to attribute the spread of psychodynamic ideas and treatments merely to the work of Freudian therapists. ${ }^{14}$ Under pressure to justify their existence and to restore soldiers to active duty, a small number of military psychiatrists occasionally pushed the hierarchical system to its limits by experimenting with such unconventional clinical techniques.

\section{Recruitment of Therapists}

In the belief that shell shock could be prevented by selection and training, the armed forces had let military psychiatry slip into decline during the interwar period and by 1939 there were only half a dozen regular officers with varying degrees of psychiatric experience, some in administrative roles. This neglect led to a key appointment. On the outbreak of war, J R Rees, director of the Tavistock Clinic, became consultant psychiatrist to the army at home and responsible for the expansion of the service. Aware of the shortage of psychiatrists in the armed forces, Rees had begun to build up a list of potential recruits before war had been declared. ${ }^{15}$ These included Emanuel Miller (a Tavistock-trained child psychiatrist), Eddie Bennet, a decorated veteran of the First World War, and Wilfrid Bion, who had recently begun an analysis with John Rickman. Bennet, an analytical psychologist and friend of Jung, was ultimately sent to India where he organized psychiatric services for the army in South East Asia. ${ }^{16}$

The return of the British Expeditionary Force from Dunkirk in June 1940 brought with it large numbers of troops suffering from psychological and functional somatic disorders. The spectre of shell shock loomed. ${ }^{17}$ Would the British army again have to combat an epidemic of servicemen suffering from so-called war neuroses? To forestall this potentially damaging development, No. 41 General ('Neuropathic') Hospital moved to the Sandhill Park Mental Defective Colony at Bishop's Lydeard, near Taunton, in August $1940 .{ }^{18}$ Under the command of a regular RAMC psychiatrist, Colonel G W Will, ${ }^{19}$ it was designed to treat psychological disorders in an attempt to return soldiers to active duty or to employment in civilian life. The influence of Rees can be seen in many of the psychiatrists sent to work at Bishop's Lydeard. Responsible for research and teaching at the Tavistock from 1934, J A Hadfield became clinical director of the neurosis division with the rank of Lt Colonel, while other appointments included Miller, Alan Maberly and Geoffrey Thompson. Major Adrian Stephen, the psychoanalyst and brother of Virginia Woolf, was posted there and taught on the military psychiatry course for medical officers.

\footnotetext{
${ }^{14}$ Sonu Shamdasani, 'The psychoanalytic body', in Roger Cooter and John Pickstone (eds), Companion to medicine in the twentieth century, London, Routledge, 2003, pp. 307-22, on p. 308.

${ }^{15}$ The National Archives (hereafter TNA), WO32/ 13462, J R Rees, Untitled typescript of a speech (n.d.), p. 2.

${ }^{16}$ TNA, WO32/11550, Report of a conference on psychiatry in forward areas held in Calcutta, 8 to 10 August 1944.
}

\footnotetext{
${ }^{17}$ Shephard, op. cit., note 3 above, p. 171.

${ }^{18}$ TNA, WO222/759, Medical Quarterly Reports of No. 41 General Hospital, April 1941 to December 1944.

${ }^{19}$ Robert Drew, Commissioned officers in the medical services of the British army 1660-1960, Volume II, London, Wellcome Historical Medical Library, 1968, p. 224.
} 
Without any particular therapeutic protocol, No. 41 General and its successor, the Military Psychiatric Hospital, drew on methods practised during the First World War. Conventional wisdom suggested that after a short period of rest, servicemen should be rapidly re-introduced to military life by graded physical exercise and occupational therapy to prevent the development of functional symptoms. In addition, "some of the more intelligent patients" were offered sessions of persuasion and re-education "to help them understand the nature of their neurosis". A limited amount of "superficial analysis ... to discover the underlying causes of neuroses" was practised, though "deep analysis into predisposing causes of neuroses [was] not attempted in the time available". ${ }^{20}$ Yet outcomes were not impressive. In the quarter to June 1941, for example, only 39 (16 per cent) of 242 discharged patients were returned to duty in the same medical category, and 171 (71 per cent) were invalided from the forces. The introduction of group and occupational therapy (woodwork, sign writing and other handicrafts) saw improved results, though this may have been simply the effect of screening before referral to Bishop's Lydeard and the introduction of stricter discharge criteria designed to keep men in the armed forces so that they did not become a burden on the pension system. As a result, in the quarter to September 1943,526 patients (50.2 per cent) were retained in the army, though often in a lower medical category thereby limiting the roles that they could undertake. However, the introduction of psychiatric units overseas to treat those with a good prognosis saw the return-to-duty rate fall to 35.9 per cent by March 1944 because of the increasing tendency to send only chronic or severe cases to the hospital. ${ }^{21}$

\section{Hollymoor Military Hospital, Northfield}

Because Bishop's Lydeard could not cope with the growing number of servicemen suffering from war neuroses, Hollymoor Hospital at Northfield in Birmingham was transferred to the military in April 1942. Under its first superintendent Lt Colonel J D W Pearce, a Tavistock-trained psychiatrist, ${ }^{22}$ it was divided into hospital (200 beds) and training wings (600 beds): the first for physical treatments of the acute phase and the second to rehabilitate servicemen who had partially recovered.

At the end of 1942, it became the subject of a controversial and radical experiment designed by Majors Bion and Rickman to "tackle neurotic disability as a communal problem" and thereby instill self-respect and personal responsibility in soldiers who had already experienced "such therapeutic value as lies in military discipline, good food and regular care". ${ }^{23}$ Rickman, who had been in analysis with both Freud and Klein, joined the army in April 1942 and spent a few months at Bishop's Lydeard acclimatizing himself to military psychiatry. Based at the Tavistock before the outbreak of war, Bion had begun a training analysis with Rickman but not yet qualified. ${ }^{24}$ As a decorated

\footnotetext{
${ }^{20}$ TNA, WO222/759, Medical Quarterly Reports of

No. 41 General Hospital, 15 Jan. 1941, p. 3.

${ }^{21}$ Ibid., Quarterly Report to 30 September 1943; Quarterly Report to 31 March 1944.

${ }^{22}$ Tom Harrison, Bion, Rickman, Foulkes and the Northfield experiments: advancing on a different front, London, Jessica Kingsley, 2000, p. 155.
}

\footnotetext{
${ }^{23}$ W R Bion and John Rickman, 'Intra-group tensions in therapy: their study as the task of the group', Lancet, 1943, ii: 678-81, p. 678.

${ }^{24}$ Wilfrid R Bion, The long week-end 1897-1919, London, Free Association Books, 1986, p. 278; Oliver Lyth, 'Wilfrid Ruprecht Bion', Int. J. Psycho-Anal., 1980, 61: 269-73.
} 
veteran of the First World War, he possessed the military credibility that Rickman lacked. Faced with a regulated, hierarchical institution and patients who might be sent back to combat if they recovered, they decided to run the training wing of the hospital through a series of large leaderless groups, sometimes containing between 100 and 200 patients. This, they believed, would devolve a measure of autonomy and make patients aware of their responsibility for intra-meeting conflicts and by inference for their well-being.

Bion and Rickman were not the founders of group therapy, which had been practised on a limited scale in the UK and United States. In 1935, Basil Beaumont, president of the Society for Creative Psychology, argued that group psychotherapy constituted "a serious human method of bringing psychological freedom and adjustment to people who are not able to afford an analyst, or for people who have had analytical treatment and now want to put into practice some of the help received". ${ }^{25}$ From 1938 Joshua Bierer had run groups at the newly-constructed Runwell mental hospital in Wickford, Essex. Although large, it was built on the villa system, which enabled Bierer to organize groups of fifty, which he called "communities", and smaller ones of ten, called "circles". He claimed a success rate of 87 per cent (either discharged cured or improved), ${ }^{26}$ and later set up outpatient groups. Although these results were published in the British Medical Journal for 14 February 1942, Bion and Rickman did not refer to them. In an attempt to loosen institutional ties during the pre-war period, T P Rees, medical superintendent at Warlingham Park, a large asylum, had introduced the concept of a hospital club whereby responsibility for its management was devolved to patients.

The so-called "first Northfield experiment" proved short-lived. ${ }^{27}$ After six weeks, concerned by an apparent breakdown in discipline, the authorities posted Bion and Rickman to other units. ${ }^{28}$ No attempt had been made to evaluate the effectiveness of these groups and their abbreviated nature made retrospective analysis impossible.

Major Michael Foulkes, a Frankfurt-trained psychoanalyst, was the prime mover in the second Northfield experiment. Posted to Hollymoor in April 1943 to run a ward in the training wing, he obtained permission from the new commanding officer, Lt Colonel R J Rosie, to run small groups on his free afternoons. ${ }^{29}$ They had as Rickman observed a different theoretical basis, ${ }^{30}$ being based on Foulkes' understanding of war neurosis as a function of failed unit cohesion. Breakdown in combat, Foulkes argued, followed the fracture of links with peers so that these relationships became a source of strain rather than mutual support. ${ }^{31}$ The group itself was designed to restore a soldier's self-confidence and social tolerance of army life by re-introducing him to positive communal functioning. ${ }^{32}$

\footnotetext{
${ }^{25}$ Basil Beaumont, The technique of group work, London, Favil Press, 1935, p. 5.

${ }^{26} \mathrm{~J}$ Bierer, 'Group psychotherapy', Br. med. J., 1942, i: $214-16$.

${ }^{27} \mathrm{~T}$ M Harrison and D Clarke, 'The Northfield experiments', Br. J. Psychiatry, 1992, 160: 698-708.

${ }^{28}$ Patrick B de Maré, 'Major Bion', in Malcolm Pines (ed.), Bion and group psychotherapy, London, Routledge \& Kegan Paul, 1985, pp. 108-10.

${ }^{29}$ Pat de Maré, 'Michael Foulkes and the Northfield experiment', in Malcolm Pines (ed.), The evolution of group analysis, London, Routledge \& Kegan Paul,
}

1983, p. 223; see also Harold Bridger, 'The Northfield experiment', Bull. Menninger Clinic, 1946, 10: 71-7; T F Main, 'The hospital as a therapeutic institution', Bull. Menninger Clinic, 1946, 10: 66-70.

${ }^{30}$ Wellcome Library for the History and Understanding of Medicine (hereafter WL), PP/SHF/ C3.6 Letter to S H Foulkes from J Rickman, 17 August 1945.

${ }^{31} \mathrm{WL}, \mathrm{PP} / \mathrm{SHF} / \mathrm{C} 3.8$ Notes of staff meetings led by Major Foulkes, 24 May 1945, p. 2.

${ }^{32} \mathrm{~S}$ H Foulkes, 'Group analysis in a military neurosis centre', Lancet, 1946, i: 303-5, p. 303. 
Much has rightly been made of the role of military medicine in serving Weberian notions of modernity, the tendency for social institutions to be brought under unified and routine systems of administration. ${ }^{33}$ Historians have suggested that psychiatry in particular "conformed effortlessly to the military demands of rationalization, standardization and hierarchical discipline". ${ }^{34}$ While this may have been true of busy medical units treating battle casualties, it did not always apply to specialist base hospitals in the UK where psychiatrists, seeking to rehabilitate soldiers, challenged the military hierarchy in terms of ideas and procedures. Often they were forced to act covertly or to find sympathetic commanding officers who would turn a blind eye to what some regarded as interventions likely to undermine morale or discipline. At other times, by contrast, the military authorities took advantage of their ambiguous position (in the sense that they could serve as a patient's advocate in the absence of organic symptoms and objective signs) to circumvent regulations. A "trick-cyclist", for example, might be asked to provide a spurious medical discharge for a brave but ill-disciplined soldier or to justify a transfer to a less dangerous role.

With eight to ten members, the groups run by Foulkes were more manageable than those of the first Northfield experiment. They met once a week for ninety minutes, though some patients were also seen individually. Confident of the therapeutic effects, Foulkes described outcomes as "very good. There was scarcely a case which did not benefit, whilst in a large proportion of the patients the improvement was considerable and sometimes astonishing ... the improvement was genuine and sustained." 35

Yet no objective measures were recorded, no controls tested and no follow-ups undertaken to establish how permanent were the changes identified. In a further paper, Foulkes adopted a more modest line, observing that in the six to eight weeks of treatment "we cannot reasonably expect to alter the basic pattern, nor can we undo completely the effects of the patient's experiences". ${ }^{36} \mathrm{He}$ also conceded that "it is very difficult to assess the therapeutic effects exactly at this stage on an 'objective'-e.g. statistical—basis, because there are so many variables, and in our own field of observation these variables change so rapidly". 37 The positive note struck in this and other published investigations may have been influenced by a need to maintain morale. It would not have gone down well with the military authorities had clinicians admitted that soldiers mentally scarred by combat were unlikely to return rapidly to their pre-service level of functioning.

Internal reports compiled by military psychiatrists and therapists working at Northfield were less optimistic about outcomes than published accounts. In December 1944, for example, Lt Colonel Denis Carroll, who had succeeded Rosie as the commanding officer, wrote "while some $85 \%$ [of admissions] still return to duty, some $80 \%$ are in category C2 [those whose physical or psychiatric disabilities made them fit only for home service] and this figure will increase". ${ }^{38}$ A psychoanalyst and co-director of the Institute for the

\footnotetext{
${ }^{33}$ Roger Cooter and Steve Sturdy, 'Of war, medicine and modernity: introduction', in Roger Cooter, Mark Harrison and Steve Sturdy (eds), War, medicine and modernity, Thrupp, Sutton Publishing, 1998, pp. 1-21.

${ }^{34}$ Joanna Bourke, 'Disciplining the emotions: fear, psychiatry and the Second World War', in Cooter, Harrison and Sturdy (eds), op. cit., note 33 above, pp. 225-38, p. 232.
}

\footnotetext{
${ }^{35} \mathrm{~S}$ H Foulkes and Eve Lewis, 'Group analysis: a study in the treatment of groups on psycho-analytic lines', Br. J. Med. Psychol., 1944-46, 20: 179-80.

${ }^{36}$ Foulkes, op. cit., note 32 above, p. 303.

${ }^{37}$ Ibid., p. 305.

${ }^{38}$ TNA, WO222/846, Report on the Work of the Medical Division, Military (P) Hospital, Northfield, 25 December 1944, p. 1.
} 


\section{War and the Practice of Psychotherapy}

Scientific Treatment of Delinquency before enlistment, Carroll kept an open mind about new treatments. Although he observed that "group psychotherapy has increased in popularity", Carroll concluded that "it does not appear to have been as helpful as anticipated in increasing the practicable caseload". 39

\section{The Therapeutic Community}

Whilst the First World War had demonstrated that the nation's fittest and bravest could succumb to mental breakdown, ${ }^{40}$ this lesson had largely been forgotten by 1939 . The principle was re-established during the Second World War that everyone, if subjected to intense stress of combat, would ultimately cease to function. No longer could a line be drawn between those who were regarded as constitutionally inferior and those considered innately healthy. Furthermore, it was recognized that traditional hospital regimes, when applied to psychological disorders, robbed patients of their autonomy and could impede recovery. The more, it was argued, that could be done to restore self-confidence and a sense of personal responsibility the better. Posted to command Northfield's training wing at the end of 1944, Major Harold Bridger, who had no formal training in psychiatry or psychology, set about introducing these ideas. By creating a "hospital club" (in effect an empty ward without a defined purpose), he sought to encourage patients to create their own social organization, which in turn would give them a sense of purpose and identity. ${ }^{41} \mathrm{Lt}$ Colonel Tom Main, a psychiatrist, transferred to Northfield in spring 1945, widened the scope of the experiment to include everyone in the hospital, coining the term "therapeutic community". ${ }^{42} \mathrm{He}$ later wrote that:

The treatment of the neurotic patient, who suffers from a disturbance of social relationships, cannot therefore be regarded as satisfactory unless it is undertaken within a framework of social reality which can provide him with opportunities for attaining fuller social insight and for expressing and modifying his emotional drives according to the demands of real life. ${ }^{43}$

As a result, wards were structured "not as an organization run by doctors in the interests of their own technical efficiency" but as a community "related to real tasks" to provide opportunities to identify and analyse "the inter-personal barriers which stand in the way of participation in a full community life". ${ }^{44}$ At Northfield, the dynamic process underlying the social interaction of the ward was termed "Lewinfiltration", a reference to the experiments in the social psychology of groups by Dr Kurt Lewin. ${ }^{45}$ In a therapeutic community the psychiatrist was required to renounce his traditional paternalistic role as doctor and assume that of reflective commentator and participant in daily activities. Speaking specifically of group therapy, Foulkes argued that if the "psychotherapist resists the temptation to be made a leader, he will be rewarded by [his patients] growing independence, spontaneity and

\footnotetext{
${ }^{39}$ Ibid.

${ }^{40}$ Mathew Thomson, 'Constituting citizenship: mental deficiency, mental health and human rights in inter-war Britain', in Christopher Lawrence and Anna-K Mayer (eds), Regenerating England: science, medicine and culture in inter-war Britain, Amsterdam, Rodopi, 2000, pp. 231-50, p. 241.
}

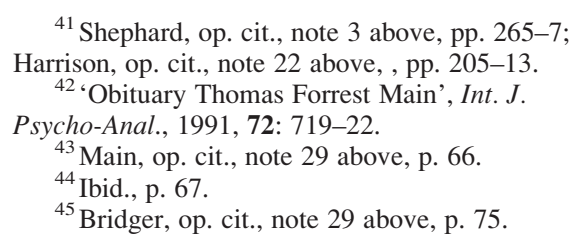


responsibility and personal insight into their social attitudes". ${ }^{46}$ This radical change in attitude towards mental illness and the status of patients was perhaps the most significant psychiatric effect of the war.

\section{Mill Hill EMS Hospital}

To provide support for specialist military hospitals, the government took over civilian establishments under the "Emergency Medical Services" (EMS) scheme. Psychiatrists from the Maudsley Hospital were recruited to the war effort, being divided between two suburban units in London. One group, led by W S Maclay as medical superintendent and including Aubrey Lewis, Eric Guttman and Maxwell Jones, was sent to a converted public school at Mill Hill. Occupational and social psychiatry was their goal. An "Effort Syndrome Unit" of 150 beds was set up under the joint directorship of Paul Wood, a cardiologist, and Jones. ${ }^{47}$ Having identified the physiological basis for his patients' symptoms, Jones believed that disorders such as effort syndrome were maladaptive learned responses. ${ }^{48}$ To provide corrective education, lectures involving groups of fifty patients were provided. However, he soon recognized that their value was limited given the general level of mistrust felt by patients towards doctors and well-established nature of symptoms. Formal instruction was abandoned in favour of discussion and the traditional barriers between doctors, nursing staff and patients were lowered, though not eliminated. ${ }^{49}$ Groups of ninety, still of an educational character, were held three times a week for two hours, while programmes of physical exercise and occupational therapy were also provided. A form of therapeutic community evolved from clinical practice, rather than being theoreticallydriven as in the first Northfield experiment. "Soldiers in general", observed Jones, "and neurotic soldiers in particular, were always on their guard against being 'got at' by those in authority" and the group discussion was a way of engaging their active participation. ${ }^{50}$ Like Hans Eysenck (see below), Jones regarded the symptoms as an essential feature of the disorder and therapy was tailored to alter the patient's attitude towards them.

Having discovered the therapeutic effects of groups, Maxwell Jones extended the principle to the Effort Syndrome Unit as a whole. By undermining the hierarchical distinctions between doctors, nurses and patients, he encouraged "a greater degree of social penetration", aided by "the temporary nature of the hospital and of the nurses who were drawn from other professions". ${ }^{51}$ However, Bridger, who visited Mill Hill before taking up his appointment at Northfield, observed that the closed system focused on the charismatic figure of Jones himself. ${ }^{52}$ This therapeutic community owed as much to social psychiatry (which assessed the patient's functioning and interactions within the context of their family, upbringing and occupation) as to any theory of psychodynamics and demonstrated that

\footnotetext{
${ }^{46} \mathrm{~S}$ H Foulkes, 'Principles and practice of group therapy', Bull.Menninger Clinic, 1946, 10: 85-9, p. 86.

${ }^{47}$ Bethlem Royal Hospital Archives, The Medical Superintendent's Report on the Organization and Work of Mill Hill Emergency Hospital to December 31 1940, p. 2.

${ }^{48} \mathrm{D}$ W Millard, 'Maxwell Jones and the therapeutic community', Freeman and Berrios
}

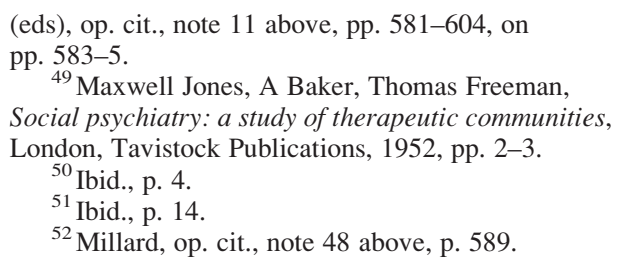




\section{War and the Practice of Psychotherapy}

progress in the wider field of psychotherapy was not tied to any particular institution or discipline. However, despite the urgings of Aubrey Lewis, Jones made little attempt to evaluate outcomes using statistical techniques. ${ }^{53}$

\section{Brief Therapy in the Field (PIE)}

The one area where psychotherapy was considered valuable even by military authorities was on the battlefield. "Forward psychiatry" was considered an effective treatment for "battle exhaustion" or what would now be termed combat stress reaction. Abreaction, or the discharge of emotion attached to a repressed experience, had been practised at special treatment centres close to the front line during the First World War by William Brown and Frederick Dillon. ${ }^{54}$ In the early days of psychoanalysis, the process of re-experiencing was in itself considered cathartic, regardless of whether the patient understood the underlying significance of the repressed memory. To encourage recall Brown used light hypnosis and claimed to have returned 91 per cent of admissions to full duty. ${ }^{55}$ Given the large numbers admitted to these units and the limited time available to each patient, these results are hard to substantiate. Other more sceptical doctors, such as William Johnson and Dudley Carmalt Jones, believed that abreaction, by re-traumatizing soldiers, interrupted a process of natural recovery. Nevertheless, this story of therapeutic success found its way into the official histories and it was widely proclaimed that 80 per cent of shell-shocked patients treated by forward psychiatry returned to operational duties with combat units. ${ }^{56}$

The system was publicized by Thomas Salmon, who introduced these methods to the American army in 1917. ${ }^{57}$ Much later the intervention was described by the acronym, PIE, to refer to the treatment's essential qualities: proximity (close to the battle) immediacy (as soon as possible after the breakdown to prevent the accretion and hardening of symptoms) and expectancy (the conviction that recovery was a natural outcome of therapy). ${ }^{58}$

During the Second World War, PIE methods were rediscovered by the British during the Western Desert campaign, and subsequently employed in Italy and northwest Europe once the Normandy beachhead had been established. Treatment in "Exhaustion Centres" (so-named to avoid medical terminology and to encourage notions of natural recovery)

\footnotetext{
${ }^{53}$ Edgar Jones, 'Aubrey Lewis, Edward Mapother and the Maudsley', in K Angel, E Jones and M Neve (eds), European Psychiatry on the Eve of War: Aubrey Lewis, the Maudsley Hospital and the

Rockefeller Foundation in the 1930s, Medical History, Supplement No. 22, London, Wellcome Trust Centre for the History of Medicine at UCL, 2003, pp. 3-38, on pp. 30-1.

${ }^{54}$ Edgar Jones and Simon Wessely, 'Psychiatric battle casualties: an intra- and inter-war comparison', Br. J. Psychiatry, 2001, 178: 242-47, p. 243.

${ }^{55}$ William Brown, 'The treatment of cases of shell shock in an advanced neurological centre', Lancet, 1918, ii: 197-200.

${ }^{56}$ W Johnson and R G Rows, 'Neurasthenia and the war neuroses', in W G Macpherson, W P Herringham,
}

T R Elliott and A Balfour (eds), History of the great war based on official documents, medical services, diseases of the war, Volume 2, London, HMSO, 1923, pp. 2-61; see also TNA, PIN15/2402, Conference on Entitlement in Neurasthenia, 10 November 1939, Dr Gordon Holmes, who had been consultant neurologist to the BEF in World War One claimed that " $86 \%$ of the men were back to the line within a fortnight or three weeks", p. 13.

${ }^{57}$ Thomas W Salmon, 'The care and treatment of mental diseases and war neuroses ("shell shock") in the British army', Mental Hygiene, 1917, 1: 509-47.

${ }^{58} \mathrm{~K}$ L Artiss, 'Human behaviour under stress: from combat to social psychiatry', Mil. Med., 1963, 128: 1011-15. 
was not uniform, depending in part on the preferences of individual medical officers. Because of the large numbers admitted to these centres during battle, sedation and graduated exercise were the most common interventions. Re-education and brief focused therapy sometimes assisted by hypnosis were also practised. As Major J E Burch of No. 1 Canadian Exhaustion Unit, which operated in Normandy, observed in September 1944, "deeper analysis is required but seldom. Abreaction has been attempted using intravenous barbiturates but this has not been found to be of value therapeutically and has been given up". 59

By contrast, Captain Patrick de Maré, who ran a 100-bed Exhaustion Centre at 31 Field Dressing Station in France and Holland during 1944, favoured abreaction sometimes assisted by light hypnosis. This reflected his own interests in psychotherapy, having been a member of the Society for Creative Psychology and undertaken twice-a-week therapy. De Maré believed that abreaction relieved:

... the man of pent-up emotions, and there is usually considerable release of affect. An attempt is then made to reinforce the ego by strong suggestion, and to "come to terms with reality"... [The soldier] is told that he has come through the incident safely, that he must try and extricate himself from the past, that as he succeeds in doing this, so the tension causing the impediment [movement and speech disorders] will go. ${ }^{60}$

He estimated that 86 per cent of admissions were sent to convalescent depots where they were downgraded to non-combatant roles. Having been demobilized from the army, de Maré trained as a group analyst and became a consultant psychotherapist at Halliwick and St George's Hospitals.

Although papers in reputable medical journals proclaimed the efficacy of PIE, the private reports of military psychiatrists were modest in their claims. In reality, most soldiers worn down by the intense stress of combat were unable to go back to fighting units after treatment. For example, between July and September 1944 Major Burch returned only 6 per cent of admissions to their units, the majority being sent to rehabilitation centres or to base duties. His successor, Major T E Dancy recorded in December 1944 that most soldiers treated there "will never again be able to face front-line service", adding that group therapy had failed to rid most men of their somatic symptoms. ${ }^{61}$ A secret report by Brigadier H A Sandiford, Director of Army Psychiatry, on a visit in 1944 to No. 39 General Hospital in Normandy also showed modest results:

Captain Henson, RAMC, neurologist, who is producing a report on 400 cases of exhaustion received by him. Preliminary analysis of 107 cases received early on in operations shows that 43 per cent had previously been treated elsewhere for exhaustion, returned to duty and relapsed. 19 per cent were under 20 years of age ... About $50 \%$ had passed through the hands of Corps' psychiatrists forward but this proportion had risen in patients received in October. ${ }^{62}$

Brigadier Sandiford had also visited No. 7 Base Psychiatric Centre at Assisi where, according to Lt Colonel Stephen MacKeith, group analytical techniques devised

59 TNA, WO222/1735, Medical Quarterly Report, No. 1 Canadian Exhaustion Unit, July 1944 to March 1945.

${ }^{60}$ Captain P B de Maré, 'Exhaustion Centre' (typescript, August 1944), p. 2.
${ }^{61}$ TNA, WO222/1735, Medical Quarterly Report, 31 December 1944, pp. 1, 4.

62 TNA, WO32/11550, 'Psychiatric service in operational theatres, report on visit to 21 Army Group', p. 1. 


\section{War and the Practice of Psychotherapy}

at Northfield were re-applied and provided "a few pointers for civilian practice". ${ }^{63}$ Yet Sandiford's "restricted" report depicted modest success with only 19 per cent of admissions discharged in the same medical category, 63 per cent being downgraded and the remainder being evacuated to the UK or other hospitals. ${ }^{64}$

\section{The York Clinic, Guy's Hospital}

The York Clinic at Guy's Hospital, set up in April 1944 by Air Commodore Robert Gillespie was the first inpatient psychiatric unit attached to a teaching hospital in the UK. ${ }^{65}$ Gillespie had trained at the Cassel Hospital and Johns Hopkins, Baltimore, before being appointed physician in psychological medicine at Guy's in 1926. Recruited into the air force on the outbreak of war, he was posted to the RAF Officers' Hospital, Torquay, to investigate the nature of breakdown among aircrew. The experience of treating men with no history of mental illness and who did not fall into the traditional asylum diagnoses led Gillespie to consider social and cultural factors in the causation and treatment of psychoneuroses. ${ }^{66}$ Designed to treat "psychological illnesses of all kinds from the mildest condition commonly called 'nerves' to the more severe illnesses involving mental alienation", the York Clinic accepted only voluntary patients. ${ }^{67}$ The first of the four wards was designed to treat psychoneurosis with access to recreational space on the ground floor where the library, occupation room and lounge were situated. With forty-three beds, much attention was spent on providing a therapeutic atmosphere: private rooms, a gymnasium and quality furnishings.

Most of the 168 patients admitted to the York Clinic during its first nine months were from the armed forces, the majority being diagnosed as anxiety states and "combat exhaustion coming a good second". Treatment was broadly-based including continuous baths, narcosis and ECT for the most disturbed patients and occupational (leather work, carpentry and model making) and individual therapy for milder cases. Two psychotherapists, including A McLeod, were employed and practised the method described by Adolf Meyer as "distributive analysis". Social activity was identified as "one of the most important therapeutic agents": "the patients ... elect committees to organize weekly dances, charades, musical evenings, debates, and games tournaments". ${ }^{68}$ Although not specifically a therapeutic community, the liberal regime and range of treatments offered marked a change from the asylum culture and represented a conscious attempt to raise the status of psychiatry and its allied disciplines.

Following the suicide of Gillespie in October 1945, Thomas A Munro, recently returned from military service in India, became the York Clinic's second director. It became part of

\footnotetext{
${ }^{63} \mathrm{~S}$ A MacKeith, 'Lasting lessons of overseas military psychiatry', J. Ment. Sci., 1946, 92: 546-7.

64 TNA, WO32/11550, No. 7 Base Psychiatric Centre, 30 September 1944.

65 'Ways and means in psychiatry', Lancet, 1945 , i: 614 .

${ }^{66}$ R D Gillespie, Psychological effects of war on citizen and soldier, New York, W W Norton, 1942, pp. 76-7.
} 


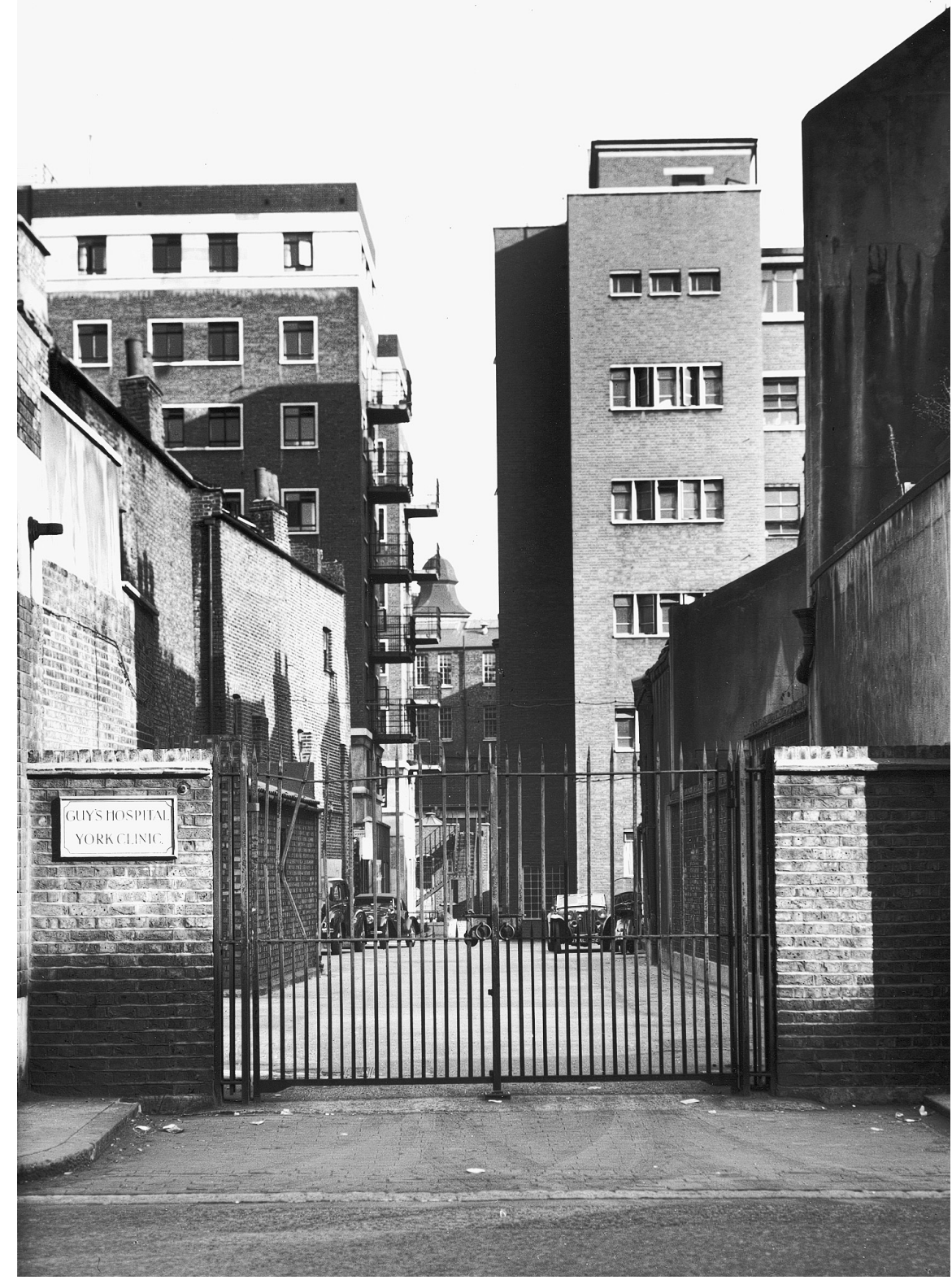

Figure 1: The York Clinic, the six-storey building to the right, situated within Guy's Hospital. Photographed in September 1955, it had become part of the NHS although it still had a number of private beds. Opened in April 1944, the treatment and management practised at the York Clinic owed much to therapeutic communities set up to treat servicemen suffering from the accumulated stress and trauma of combat. It was said to have been the first dedicated psychiatric unit within a UK teaching hospital. (Photo: Guy's Hospital.) 


\section{War and the Practice of Psychotherapy}

the NHS in 1948 when fifteen of the forty-one beds were allocated to the health service. Once the war had ended, service patients were replaced by civilians and staff were presented with a different set of priorities; they were required to assess "the personality of the patient, his emotional and instinctive life, the domestic, economic and social background of his life, the specific way in which he has tried to establish an equilibrium in his own personality and tolerable working arrangements within his surroundings". ${ }^{69}$ In 1956, when 340 patients were discharged, 181 (53 per cent) were private and 159 (47 per cent) were NHS, though almost two-thirds were "drawn from the managerial and professional classes with only a sprinkling of manual and unskilled workers". ${ }^{70}$ The atmosphere of the clinic was described by J J Fleminger, who arrived in 1955 to find:

... a compact unit on a "domestic scale" where a relatively small staff knew each other well ... The sister in charge of the York Clinic entertained us to tea with sandwiches and cakes every afternoon at half-past three. The York Clinic had its own kitchen and chef ... It was all not merely comfortable-it was charming. ${ }^{71}$

\section{Post-War Organization of Psychotherapy}

In 1942, at the behest of the Ministry of Health, C P Blacker surveyed psychiatric outpatient facilities in England and Wales, comparing wartime usage with that for $1938 .^{72}$ Designed to identify the needs of the civilian population in peacetime, Blacker made no specific recommendations for psychotherapy, though he addressed the roles of psychiatric social workers, psychologists and occupational therapists. Sympathetic to psychodynamic approaches and having undertaken a brief training at the Tavistock Clinic, Blacker recognized that the psychotherapy profession faced a credibility gap with the public and medicine. Popular perceptions of "analytic procedures", he suggested in 1946, were regarded as taking:

... too long to produce results which, at best, are dubious ... valuable time is wasted by psychotherapists on chronic neurotics and psychopaths who are unhelpable, while the needs of the average normal member of society pass unrecognized. Analytic methods of psychotherapy are sometimes spoken of as if they were a decadent and modern fad. ${ }^{73}$

"So prevalent" did Blacker consider these beliefs, however ill-founded, that they would "obstruct the co-ordination of the country's psychiatric services in any scheme designed to provide minimum standards". Indeed, in 1941 the clinic set up in London by Edward Glover and other psychoanalysts to treat those traumatized by air-raids had been forced to close

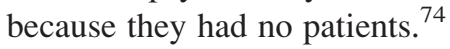

Most psychiatrists and psychologists recruited into the RAMC left the forces once peace was declared. Bion undertook a training analysis with Melanie Klein and, like Rickman, went into private practice. Foulkes was appointed consultant psychotherapist at the

\footnotetext{
69 Thomas A Munro, 'Report on the York Clinic for Psychological Medicine' (typescript, 9 July 1948), p. 2.

${ }^{70} \mathrm{M}$ Woodside, 'York Clinic 1956, calculations and comments' (typescript October 1958), p. 3.

${ }^{71}$ J J Fleminger, 'Psychiatry at Guy's', Guy's Hospital Gazette, 1983, 97: 296-302, p. 301.
}

\footnotetext{
${ }^{72} \mathrm{C}$ P Blacker, Neurosis and the mental health services, London, Oxford University Press, 1946.

${ }^{73}$ Ibid., p. 47.

${ }^{74}$ P Roazen, Oedipus in Britain: Edward Glover and the struggle over Klein, New York, Other Press, 2000, pp. 144-5.
} 
Maudsley Hospital. Bridger trained as a psychoanalyst with Paula Heimann and became a key member of the Tavistock Institute of Human Relation's consultancy team working in industry and other large organizations. ${ }^{75}$ Trained by Michael Balint, Main qualified as a psychoanalyst, as did Lt Colonel J D Sutherland, the senior psychiatrist attached to the research and training centre of the War Office Selection Boards, and became medical director of the Tavistock Clinic.

Futhermore, the Second World War encouraged the expansion of academic departments of psychiatry and within them the appointment of psychotherapy specialists. However, this was not without precedent. William Brown had been consultant psychotherapist at King's College Hospital from 1925 to $1931,{ }^{76}$ and W Lindesay Neustatter had served as the Maudsley's therapist from 1931. Seven years later, he became physician in psychological medicine to Queen Mary's Hospital for the East End. ${ }^{77}$ In 1946, Frederick Dillon became consultant physician in psychological medicine at University College Hospital having worked as a therapist while a clinical assistant under Bernard Hart. ${ }^{78}$ Yet, by 1950 there were still relatively few consultant psychiatrists in London teaching hospitals and fewer psychotherapists. ${ }^{79}$ The appointment of psychotherapy specialists appears to have been a feature of the 1960s and 1970s rather than the immediate post-war period. For example, Guy's Hospital Medical School, which had a sound reputation for psychiatry, following the work of R D Gillespie, D Stafford-Clark and J J Fleminger, did not elect its first consultant psychotherapist, Derry Macdiarmid, until 1981, though he had been appointed senior lecturer in psychotherapy at the Middlesex Hospital four years earlier.

Why, then, was psychotherapy slow to develop in the post-war period? First, there was resistance from the medical profession. Despite wartime publications suggesting positive clinical outcomes, the absence of a convincing scientific explanation for symptoms or treatments gave critics ready ammunition. Yet therapists themselves did little to introduce procedures and hypotheses to a wider audience and no concerted attempt was made to integrate the embryonic profession with other disciplines. In the 1950s, from both a theoretical standpoint and in terms of training, psychoanalysis, whether Freudian or Jungian, held a virtual monopoly over individual therapy. Jargon (terms such as super-ego, id, cathexis, Oedipus complex and so forth) introduced to gain intellectual credibility were probably counterproductive in so far as they obfuscated meaning and inhibited dialogue with other disciplines. Furthermore, many key analysts, such as Anna Freud and Melanie Klein, were European émigrés. Their intra-psychic model of neurosis did not resonate with the British empirical tradition, which placed greater emphasis on the senses (and instruments that extend their range) and experiment to frame ideas. Indeed, the object-relations school (as expressed by Donald Winnicott, John Bowlby, W R D Fairbairn and Charles Rycroft) was in part a response to what was essentially a deductive system in which fundamental principles (largely derived from Freud) were used to frame knowledge.

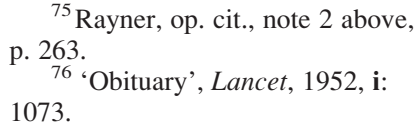

\footnotetext{
${ }^{77}$ Pines, op. cit., note 11 above, p. 226.

78 'Obituary', Lancet, 1965, i: 1077.

${ }^{79}$ Medical Directory for 1949, Part 2, London, J \& A Churchill, 1949, pp. 398-405.
} 


\section{War and the Practice of Psychotherapy}

A desire to follow a pure stream of Freudian thought deterred the British PsychoAnalytic Society from seeking collaborative ventures with medical schools or psychology departments. For the small number of demobilized psychiatrists whose interest had been captured by psychodynamic ideas during wartime, there were few training opportunities apart from the Institute of Psycho-Analysis. Although in 1936 Jungian therapists had begun discussions on setting up their own training body, a constitution for the Society of Analytical Psychologists was not framed until 1946 with the return of servicemen such as Brigadier E A Bennet. Not until 1951 was the British Association of Psychotherapists (BAP) set up with Freudian and Jungian wings, with a reduced training requirement of three-times a week therapy.

By its very nature, psychoanalysis could never flourish as a mass movement. The barriers to entry were high: a prior qualification in medicine or psychology was usually required, while an extended period of five-times a week therapy imposed financial and occupational limits. As a result, membership of the British Psycho-Analytic Society rose steadily rather than spectacularly from 92 in 1939 to 129 in 1950 and reached 175 by $1954,{ }^{80}$ though these figures included some analysts resident in the United States and the Commonwealth, and others who had retired. Given the demanding training, it was difficult for the Society to have grown at anything other than a sedate pace, while the focus of its membership in London inhibited its expansion to other regions of the UK. Furthermore, psychoanalysis was a self-contained system of ideas and beliefs, more a way of life than a profession. Unable to meet the diverse and immediate needs of the National Health Service (NHS), it promoted itself as a higher authority, training and supervising mental health professionals, while attempting to provide intellectual guidance through the Hogarth Press monographs and the International Journal of Psycho-Analysis. The rise of evidence-based medicine, alternative models of mental illness and pressure to provide cost-effective clinical services during the 1980s undermined its claim for pre-eminence.

It has been argued that by creating a demand for psychotherapy, which psychiatrists and general practitioners could not supply once peace had returned, the Second World War gave clinical psychologists the opportunity to break the medical monopoly. ${ }^{81}$ The need for brief focused therapies, delivered in outpatient clinics to treat less severe disorders, allowed this university-based profession to occupy new territory. In addition, a serious challenge to analytical theory came from clinical psychologists, such as Hans Eysenck at the Maudsley, who offered behavioural explanations for psychological disorders. Based on laboratory studies of conditioning and on modern learning theory, neurotic symptoms were conceived as the disorder rather than symptoms of unconscious conflict about introjected parental figures or instinctual drives. In contrast to psychoanalysis, Eysenck's system had the appeal that it could be learned, practised and measured relatively easily. Treatment strategies included desensitization (or counter-conditioning), flooding (extended exposure to the conditioned stimulus) and modelling (the presentation of coping strategies). In an increasingly cost-conscious NHS required to demonstrate the effectiveness of clinical interventions, this form of brief focused therapy leant itself to statistical

\footnotetext{
${ }^{80}$ Int. J. Psycho-Anal., 1939, 20: 504-6; Int. J. Psycho-Anal., 1950, 31: 311-13; Int. J. Psycho-Anal., 1954, 35: 471-3.
}

\footnotetext{
${ }^{81}$ Mathew Thomson, 'The psychological body', in Cooter and Pickstone (eds), op. cit., note 14 above, pp. 291-306, p. 300
} 


\section{Edgar Jones}

evaluation. Indeed, as a result of random-controlled trials, its successor cognitivebehaviour therapy (CBT) has become the standard intervention for post-traumatic stress disorder (PTSD).

Growth of dynamic psychotherapy in the embryonic health service was gradual. Although services were introduced as a result of doctor initiatives, psychiatric social workers also played a significant role during the 1960s and 1970s. Concerned to rehabilitate patients often institutionalized by lengthy admissions and to find ways of preventing relapse, they sought psychodynamic ideas that could be adapted to fit models of brief focused psychotherapy. Client-centred and task-oriented therapies were devised to tackle practical problems in relatively short periods of time. The Family Welfare Association, an organization that employed social workers trained in psychotherapy, played an important part in broadening the application of these initiatives. ${ }^{82}$

As regards training, London dominated in the post-war period. Not only were the Freudians, Jungians and BAP located in the capital but so too the Lincoln Clinic and Centre for Psychotherapy (founded in 1967 by Lionel Monteith), the Institute of Group Analysis (set up in 1971 by S H Foulkes) and the London Centre for Psychotherapy (1974). Not until twenty-five years after the war did Scotland get its own organizations: the Scottish Institute for Human Relations founded in 1970 by Sutherland after his retirement from the Tavistock, and the Scottish Association of Psychoanalytical Psychotherapists (1972).

\section{Post-War Therapeutic Communities}

By raising questions about the nature of certain psychological disorders, the war influenced the design of specialist treatment centres in the NHS. Main, for example, put ideas framed during wartime into practice when he was appointed director of the Cassel Hospital. A therapeutic community was also established by Maxwell Jones as director of the Industrial Neurosis Unit at Belmont Hospital, Sutton (later re-named the Henderson Hospital), which initially accommodated 100 patients in four wards, though occupancy halved over the next twenty years as its activities broadened. In 1947, because his training had been in mainstream psychiatry and wishing to improve his "skills in group psychotherapy and psychodynamics generally", Jones entered a training analysis with Melanie Klein, though three years later ended this before qualification. ${ }^{83}$

The idea that the community itself might serve as instrument of therapy, developed at Northfield and Mill Hill where it was designed to treat neuroses, was also taken up in modified form by asylums for those who suffered from chronic disorders or psychosis. More liberal regimes, for example, were adopted at Fulborn from 1953 as a result of initiatives by David Clark (who had worked with David Henderson at the Royal Edinburgh Hospital and Foulkes at the Maudsley) and at Claybury following the appointment of Dennis Martin in $1955^{84}$

\footnotetext{
${ }^{82}$ Malan, op. cit., note 12 above, p. 229. p. 590.
}

\footnotetext{
${ }^{84}$ Nick Manning, The therapeutic community movement: charisma and routinization, London, Routledge, 1989, p. 26.
} 


\section{War and the Practice of Psychotherapy}

Therapeutic communities were set up at Halliwick Hospital and at Atkinson Morley's, the neuro-psychiatric inpatient unit of St George's Hospital. Professor A H Crisp was the driving force behind the latter where group analysts, Patrick de Maré and Malcolm Pines were recruited as consultant psychotherapists. When J P Watson was appointed to the chair of psychiatry at Guy's in 1974, he brought with him some of the ideas worked out at Atkinson Morley's Hospital. Under Watson and B K Rosen, George Savage ward in the York Clinic evolved as a form of therapeutic community and functioned as such until the building was vacated in 1997.

\section{Conclusions}

The Second World War did advance the development of psychotherapy in the UK both as a recognized form of treatment and as a profession, though its impact was often delayed or slow to take effect. The conflict provided seemingly robust statistical evidence that individual and group therapies could address the immediate psychological effects of battle and their longer-term consequences. Publications in leading medical journals buttressed its claim for scientific respectability. The apparent absence of war neuroses in returning veterans, in contrast to the shell shock epidemic of the First World War, reinforced this impression of effectiveness. The widespread deployment of psychiatrists and psychologists in the armed forces raised the general profile of psychological medicine among doctors and servicemen. Although much suspicion remained, the market for psychotherapy had been extended, providing new opportunities for mental health professionals. The decision of a number of ex-military psychiatrists, such as Bion, Main and Sutherland, to train at the Institute of Psycho-Analysis both broadened its intellectual basis and added a measure of credibility.

Having established their pedigree in the army, groups became an accepted form of treatment in the NHS. Equally, the concept of the therapeutic community found a place in a state-funded health service and was seen at its fullest expression in the Cassel, Halliwick and Henderson Hospitals. In dilute form, these ideas spread to psychiatric wards opened in general hospitals where groups, occupational therapy and systems of key workers reflected a more liberal attitude towards patients and psychological disorders. ${ }^{85}$ Because of costlimitations, provision for individual therapy within the NHS remained limited in the postwar period. Confined to a small number of specialist units, such as the Tavistock Clinic, or to brief, focused therapies, virtually all in-depth, long-term treatment remained in the private sector.

The boost given to the academic credibility of psychiatry by the war allowed teaching hospitals to expand departments of psychological medicine and these commonly included a consultant psychotherapist, though most remained part-time. The creation of the Royal College of Psychiatrists in 1971 and its membership examinations, which subsumed the Diploma in Psychological Medicine, saw psychodynamic

\footnotetext{
${ }^{85}$ Ibid.; Kathleen Jones, Mental health and social policy 1845-1959, London, Routledge \& Kegan Paul, 1960, p. 168.
} 


\section{Edgar Jones}

ideas and practices formally incorporated in the training of junior doctors. Nevertheless, the formal introduction of psychotherapy training was delayed when it was discovered that there were insufficient consultants outside London to provide nationwide coverage. In the event, as Pines has argued, the accompanying training scheme broke the monopoly of the private psychoanalytic institutes in providing a recognized qualification to practice. $^{86}$

\footnotetext{
${ }^{86}$ Pines, op. cit., note 11 above, p. 229.
} 